\title{
International Observational Survey of the Effectiveness of Personal Protective Equipment during Endoscopic Procedures Performed in Patients with COVID-19
}

\author{
Ryota Niikura $^{a}$ Mitsuhiro Fujishiro $^{b}$ Yousuke Nakai $^{a, c}$ Koji Matsudad \\ Takuya Kawahara ${ }^{\mathrm{e}}$ Atsuo Yamada ${ }^{a}$ Yosuke Tsuji ${ }^{a}$ Yoku Hayakawa ${ }^{a}$ \\ Kazuhiko Koike ${ }^{a}$ \\ aDepartment of Gastroenterology, Graduate School of Medicine, The University of Tokyo, Tokyo, Japan; \\ bDepartment of Gastroenterology and Hepatology, Nagoya University Graduate School of Medicine, Nagoya, Japan; \\ 'Department of Endoscopy and Endoscopic Surgery, Graduate School of Medicine, The University of Tokyo, Tokyo,

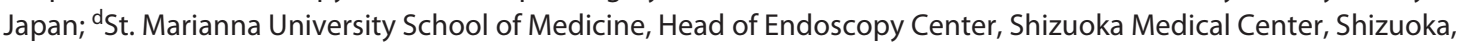 \\ Japan; ${ }^{~}$ Clinical Research Promotion Center, The University of Tokyo Hospital, Tokyo, Japan
}

\section{Keywords}

Novel coronavirus disease 2019 · Endoscopy ·

Gastrointestinal bleeding · Personal protective equipment

\begin{abstract}
Introduction and Aims: This international survey was performed to evaluate the cumulative incidence of nosocomial novel coronavirus disease 2019 (COVID-19) among healthcare professionals during endoscopic procedures. Methods: We performed an international web-based self-reported questionnaire survey. Participants completed the questionnaires every week for 12 weeks. The questionnaire elicited responses regarding the development of COVID-19 and details of the personal protective equipment (PPE) used. $\boldsymbol{R e}$ sults: All 483 participants were included in the analysis. Participants had a mean age of 42.3 years and comprised $68.3 \%$ males. The geographic distribution of the study population was Asia (89.2\%), Europe (2.9\%), North and South America (4.8\%), Oceania ( $0.6 \%)$, and Africa (1.5\%). The most common endoscopy-related role of the participants was endoscopist (78.7\%), and $74.5 \%$ had $>10$ years of experience. Fourteen
\end{abstract}

karger@karger.com www.karger.com/dig

Karger $\stackrel{\text { ' }}{5}$

BOPEN ACCESS
(C) 2021 The Author(s)

Published by S. Karger AG, Basel

This is an Open Access article licensed under the Creative Commons Attribution-NonCommercial-4.0 International License (CC BY-NC) (http://www.karger.com/Services/OpenAccessLicense), applicable to the online version of the article only. Usage and distribution for commercial purposes requires written permission. participants had performed 83 endoscopic procedures in patients positive for COVID-19. During the mean follow-up period of 4.95 weeks, there were no cases of COVID-19 when treating COVID-19 positive patients. The most common PPE used by participants treating patients with COVID-19 was a surgical mask plus N95 mask plus face shield, goggles, cap, long-sleeved isolation gown, and single pair of gloves. The most common PPE used by participants treating patients without COVID-19 was a surgical mask, no face shield but goggles, cap, long-sleeved isolation gown, and single pair of gloves during all endoscopic procedures. Conclusions: The risk of COVID-19 transmission during any endoscopic procedure was low in clinical practice. 02021 The Author(s).

Published by S. Karger AG, Basel

\section{Introduction}

The morbidity and mortality of novel coronavirus disease 2019 (COVID-19) are increasing worldwide. The virus responsible for this disease, severe acute respiratory syndrome coronavirus-2 (SARS-CoV-2), is highly infec- 
tious and causes nosocomial infection in healthcare professionals [1]. Especially, endoscopic procedures have a potentially high risk for healthcare professionals due to transmission via aerosol from COVID-19 patients [2-7]. In addition, SARS-CoV-2 has also been detected in stool specimens, suggesting a possible risk of fecal-oral transmission [8], similar to SARS $[9,10]$. However, although endoscopic procedures pose a risk of COVID-19 transmission, they are often necessary for diagnosis and treatment of gastrointestinal (GI) bleeding, malignancies, obstructive jaundice, and cholangitis.

Recently, a research group in Italy [11] and the World Endoscopy Organization [12] performed a hospitalbased email questionnaire survey among endoscopy units and clarified the current status of personal protective equipment (PPE) use when performing endoscopic procedures in patients with a positive diagnosis or suspected COVID-19. Although these data represent very important initial reports, we considered the further necessity of data regarding the type of PPE used during endoscopic procedures in patients with different risks of COVID-19 transmission. The incidences of SARS-CoV-2 genomic mutations and clinical COVID-19 reportedly vary among geographic regions [13]. Therefore, we designed an international web-based questionnaire survey for endoscopyrelated healthcare professionals (UMIN000040162) consisting of 16 questions regarding the use of PPE, such as surgical masks, face shields, goggles, gowns, and gloves. The aims of this survey were to evaluate cumulative shortterm incidence rates of COVID-19 and to share information among healthcare providers regarding the appropriate PPE use to prevent COVID-19 transmission.

\section{Methods}

\section{Design and Participants}

We performed an international web-based questionnaire survey among endoscopy-related healthcare professionals, including endoscopists, nurses, laboratory technicians, and endoscopy reprocessing technicians working in the endoscopy suite. Participants were invited to join the survey by the principal investigators related to personal communication and World Endoscopy Organization volunteer members and were enrolled by snowball sampling methods. The survey began on April 15, 2020, and ended on August 8, 2020. Participants completed web-based questionnaires every week for 12 weeks, prompted by automated reminder emails using Google Forms ${ }^{\circledR}$. This study was approved by the Ethics Committee of the University of Tokyo Hospital (No. 2020046NI).

Web-Based Questionnaire

The web-based questionnaire included items regarding COVID-19 development, age, sex, role (endoscopist, nurse, laboratory
Table 1. Participant characteristics $(n=483)$

\begin{tabular}{|c|c|}
\hline Variable & $N(\%)$ \\
\hline Age, mean \pm standard deviation, years & $42.3 \pm 9.0$ \\
\hline Sex, female/male/no response & $\begin{array}{l}151(31.3) / 330(68.3) / \\
2(0.4)\end{array}$ \\
\hline \multicolumn{2}{|l|}{ Geographic area } \\
\hline Asia & $431(89.2)$ \\
\hline Europe & $14(2.9)$ \\
\hline North/South America & $23(4.8)$ \\
\hline Oceania & $3(0.6)$ \\
\hline Africa & $7(1.5)$ \\
\hline No response & $5(1.0)$ \\
\hline \multicolumn{2}{|l|}{ Role in endoscopic procedures } \\
\hline Endoscopist & $380(78.7)$ \\
\hline Nurse & $75(15.5)$ \\
\hline Laboratory technician & $24(5.0)$ \\
\hline Cleaner & $2(0.4)$ \\
\hline No response & $2(0.4)$ \\
\hline \multicolumn{2}{|l|}{ Years of experience } \\
\hline$<5$ years & $44(9.1)$ \\
\hline 5 to $<10$ years & $77(16.0)$ \\
\hline$\geq 10$ years & $360(74.5)$ \\
\hline No response & $2(0.4)$ \\
\hline \multicolumn{2}{|l|}{ Endoscopic procedures performed } \\
\hline in COVID-19 patients & $14(2.9)$ \\
\hline \multicolumn{2}{|c|}{ Endoscopic procedure performed in non-COVID-19 patients* } \\
\hline EGD & 401 \\
\hline Colonoscopy & 342 \\
\hline ERCP and EUS & 211 \\
\hline Upper GI hemostasis & 79 \\
\hline Lower GI hemostasis & 45 \\
\hline Upper GI ESD & 104 \\
\hline Lower GI ESD & 49 \\
\hline
\end{tabular}

EGD, esophagogastroduodenoscopy; ERCP, endoscopic retrograde cholangiopancreatography; EUS, endoscopic ultrasound; GI, gastrointestinal; COVID-2019, coronavirus disease 2019; ESD, endoscopic submucosal dissection. ${ }^{*}$ Multiple responses allowed.

technician, and endoscopy reprocessing technician), geographical area (North America, South America, Africa, Asia, Europe, and Oceania), number of years of experience, PPE (mask and face shield, goggles and face shield, cap, gown, and gloves), endoscopic procedures (esophagogastroduodenoscopy [EGD], colonoscopy, endoscopic retrograde cholangiopancreatography [ERCP], endoscopic ultrasound [EUS], endoscopic hemostasis, and endoscopic submucosal dissection [ESD]) performed in patients with and without confirmed COVID-19, and PPE replacement frequency (after each procedure, every day, 1-7 day, every week). N95 masks were defined as N95 (US NIOSH-42CFR84), FFP2 (Europe EN 149-2001), KN95 (China GB2626-2006), P2 (Australia/New ZealandAS/NZA1716:2012), Koreafirstclass(KoreaKMOEL-2017-64), and DS (Japan JMHLW-Notification 214, 2018) masks. The details of the questionnaire are shown in online suppl. Table 1; for all online suppl. material, see www.karger.com/doi/10.1159/000513714. 
Fig. 1. COVID-19 pandemic during study period. COVID-19, coronavirus disease 2019.

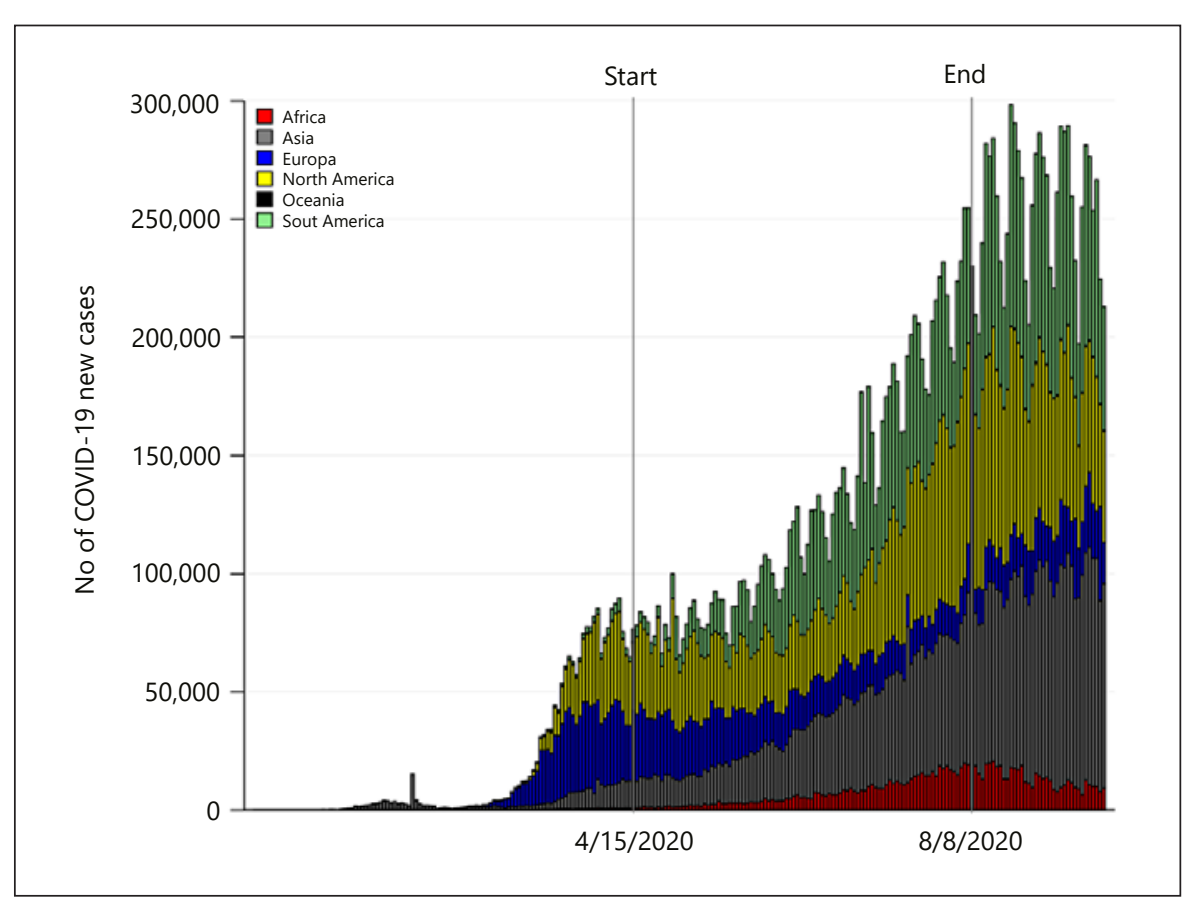

Personal Protective Equipment Evaluation

We evaluated each PPE for protection of the mouth, eyes, body, and hands and defined each as mask and face shield, goggles and face shield, cap and gown, and gloves. We also defined the minimum and maximum use of each PPE category as follows. For the mask and face shield category, the minimum PPE use consisted of a surgical mask, followed by N95 mask, and the maximum was N95 mask plus face shield. Regarding goggles and face shields, the minimum was no goggles or face shield, followed by face shield but no goggles, and goggles but no face shield; the maximum PPE was use of both goggles and face shield. For caps, the minimum and maximum were no use and use of a cap, respectively. Regarding gowns, the minimum was short-sleeved vinyl-type gown, followed by short-sleeved vinyl-type gown plus arm covers, and long-sleeved vinyl-type gown; the maximum was longsleeved isolation-type gown. For gloves, the minimum and maximum uses were a single pair and double pair of gloves, respectively.

\section{Statistics}

The full analysis set included participants who had not been diagnosed with COVID-19 at baseline to exclude potential cases of community-acquired or nosocomial infection not related to endoscopic procedures. The primary outcome was the incidence of $\mathrm{CO}$ VID-19 when treating COVID-19 positive patients, defined as a self-reported positive PCR test in the absence of close contact with an infected subject other than patients among participants who performed endoscopic procedures for COVID-19 positive patients; this was censored at the date of completion of the final questionnaire. The secondary outcome was the incidence of COVID-19 when treating patients without confirmed COVID-19.

The Kaplan-Meier method was used to estimate the cumulative incidence of COVID-19 over a 12-week period from the start to questionnaire response was calculated. A number of COVID-19 new cases were evaluated using public site data (https://github. com/owid/covid-19-data/tree/master/public/data). The statistical analyses were performed using SAS software (version 9.4; SAS Institute, Cary, NC, USA).

\section{Results}

From April 15 to August 8, 2020, a total of 488 participants were invited to join the survey. After excluding 5 because of a diagnosis of COVID-19 at baseline, 483 participants were included in the analysis. Of 483 participants, 103 participants (21.3\%) completed the questionnaire during the 12 weeks of the study. The number of COVID-19 new cases during the study period is shown in Figure 1.

\section{Participant Characteristics and Endoscopic Procedures}

The participants had a mean age of 42.3 years and comprised 68.3\% (330/483) males. The distribution according to geographic area was as follows: Asia (89.2\%), Europe (2.9\%), North and South America (4.8\%), Oceania $(0.6 \%)$, and Africa (1.5\%). The most common endoscopy-related role of the participants was endoscopist $(78.7 \%)$, and $74.5 \%$ had more than 10 years of experience. The participants had performed EGD (401), colonoscopy (342), ERCP and EUS (211), upper GI hemostasis (79), lower GI hemostasis (45), upper GI ESD (104), and lower GI ESD (49; multiple responses included) (Table 1). 

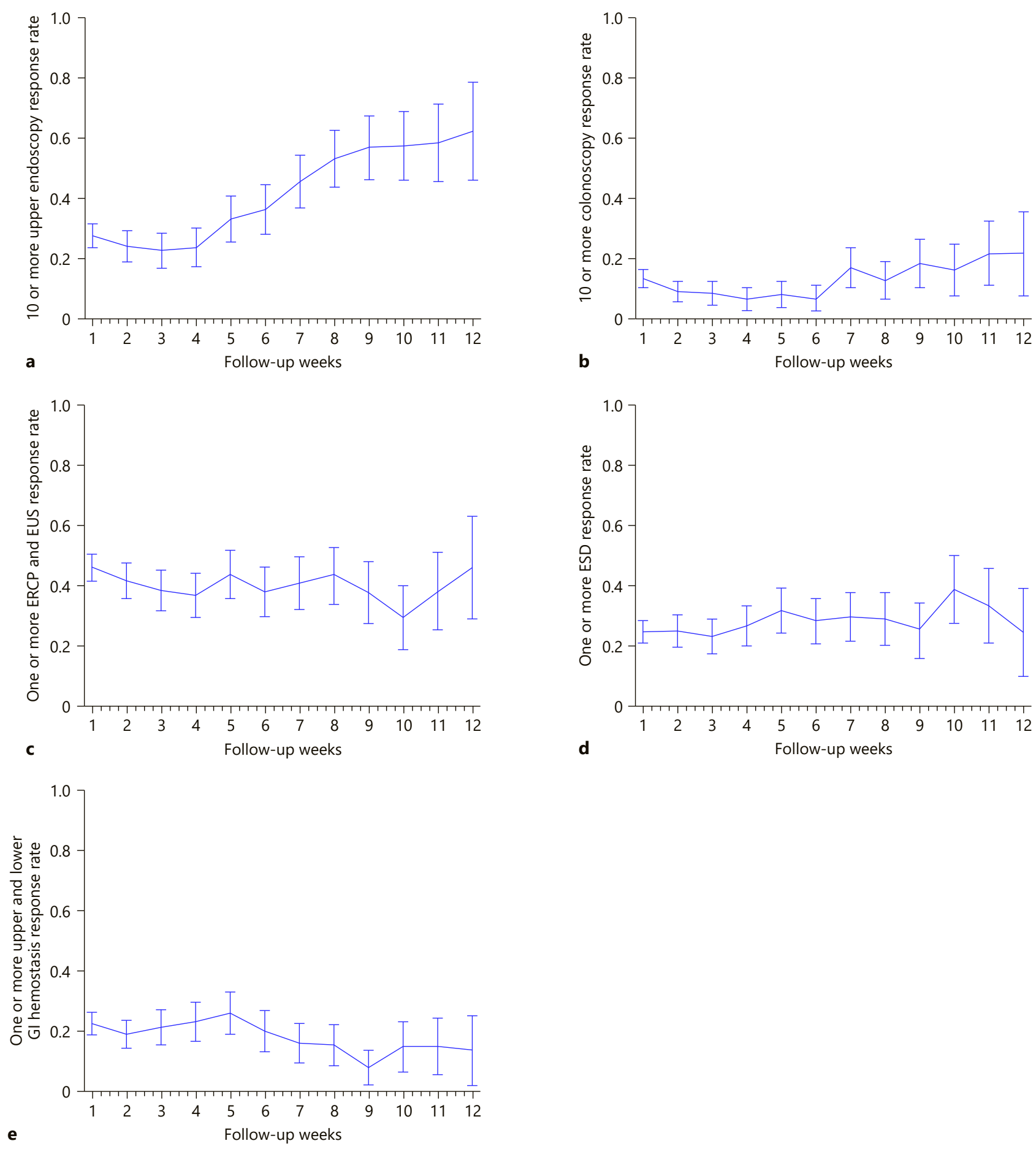

Fig. 2. Change of endoscopic procedure volume during this study period. Ten or more upper endoscopy (a), 10 or more colonoscopy (b),, 1 or more ERCP and EUS (c), 1 or more ESD (d), 1 or more upper and lower GI hemostasis (e). Bar shows 95\% confidence interval. COVID-19, coronavirus disease 2019; GI, gastrointestinal; EUS, endoscopic ultrasound; ESD, endoscopic submucosal dissection. 

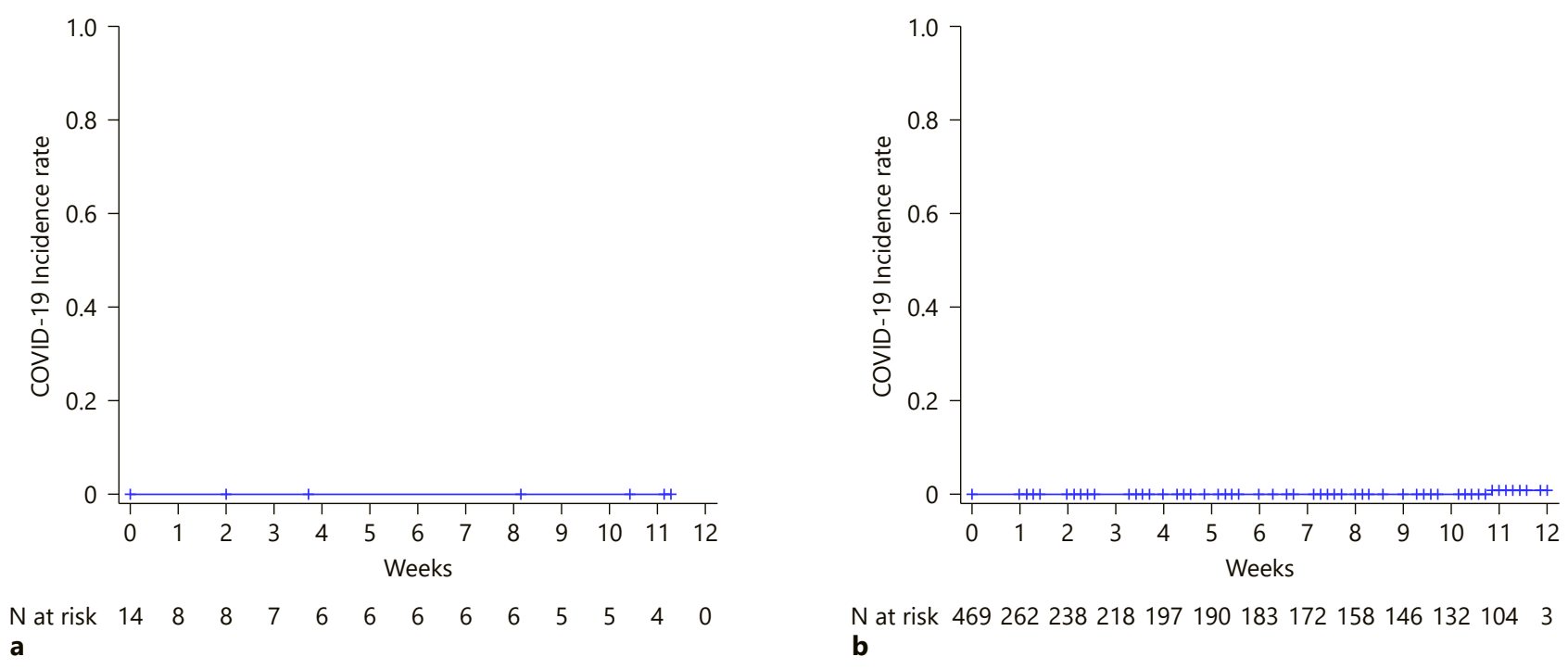

N at risk 4692622382181971901831721581461321043 b

Fig. 3. COVID-19 incidence when treating COVID-19 positive patients (a), COVID-19 incidence when treating patients without confirmed COVID-19 (b). COVID-19, coronavirus disease 2019.

Change of each endoscopic procedure volume during this study period is shown in Figure 2. EGD volume was increased (Fig. 2a), and other procedure volumes were same level at beginning and end of the study (Fig. 2b-e).

\section{Coronavirus Disease-19 Incidence and the Minimum} and Most Common Personal Protective Equipment

Used When Treating Coronavirus Disease-19 Positive

Patients

Fourteen participants performed 83 endoscopic procedures in patients with a positive diagnosis of $\mathrm{CO}$ VID-19. None of these participants developed COVID-19 over the mean follow-up period of 4.95 weeks (Fig. 3a). The distribution according to geographic area was as follows: Asia, 43\%; Europe, 22\%; North and South America, 21\%; Oceania, 7\%; and Africa, 7\%. The procedures performed were EGD by 11 participants, colonoscopy by 7 , ERCP and EUS by 10, hemostasis during EGD by 6 , hemostasis during colonoscopy by 3 , and upper GI ESD by 2. The details are shown in Table 2.

The minimum PPE used was a surgical mask (21\%), face shield but no goggles (14\%), no cap (43\%), shortsleeved vinyl-type gown (7\%), and single pair of gloves (64\%). The most common PPE used was a surgical mask plus N95 mask (36\%) or N95 mask (36\%), face shield but no goggles (50\%), cap (57\%), long-sleeved isolation-type gown (71\%), and single pair of gloves (64\%) (Table 2).
Coronavirus Disease-19 Incidence and the Minimum and Most Common Personal Protective Equipment Used when Treating Patients without Confirmed Coronavirus Disease-19

One participant who treated patients without confirmed COVID-19 developed COVID-19 over the mean follow-up period of 4.45 weeks (Fig. 3b). The minimum and most common PPE use with regard to masks was use of a surgical mask during all endoscopic procedures. The minimum PPE regarding face shields and goggles was no use of a face shield or goggles during all endoscopic procedures. The most common PPE use regarding face shields and goggles was no use of face shield but use of goggles. The minimum and most common PPE use regarding caps was use of a cap except for ESD. The minimum and most common PPE regarding gowns was no use of a gown and use of a long-sleeved isolation-type gown, respectively, during all endoscopic procedures. The minimum and most common PPE use regarding gloves was a single pair of gloves (Table 3 ).

\section{Change of Personal Protective Equipment \\ Replacement Frequency}

Change of mask, cap, and gown replacement frequencies were same level at beginning and end of this study (Fig. 4). Most common replacement frequency was every day in mask and cap and each procedure in gown, respectively. 
Fig. 4. Change of personal protective equipment replacement frequency. Mask (a), $\operatorname{cap}(\mathbf{b})$, and gown (c).

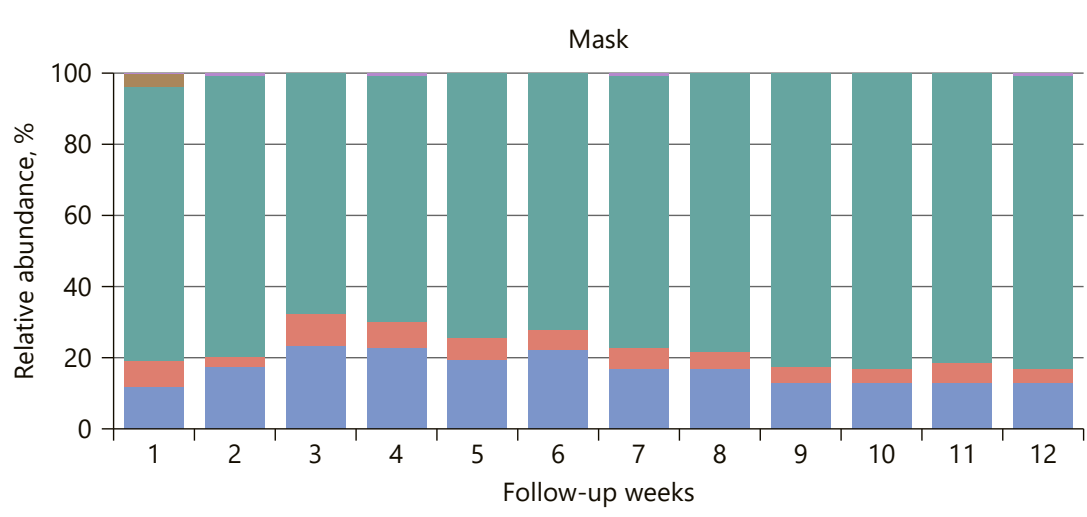

a

1-7 day After each procedure Every day $\square$ Every week $\square$ Missing

Cap

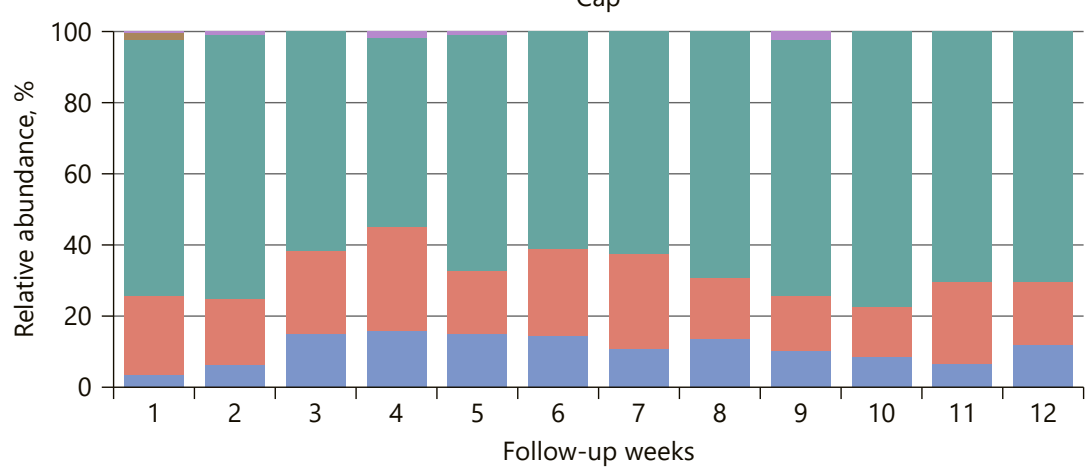

b $\square$ 1-7 day $\square$ After each procedure $\square$ Every day $\square$ Every week $\square$ Missing

Gown

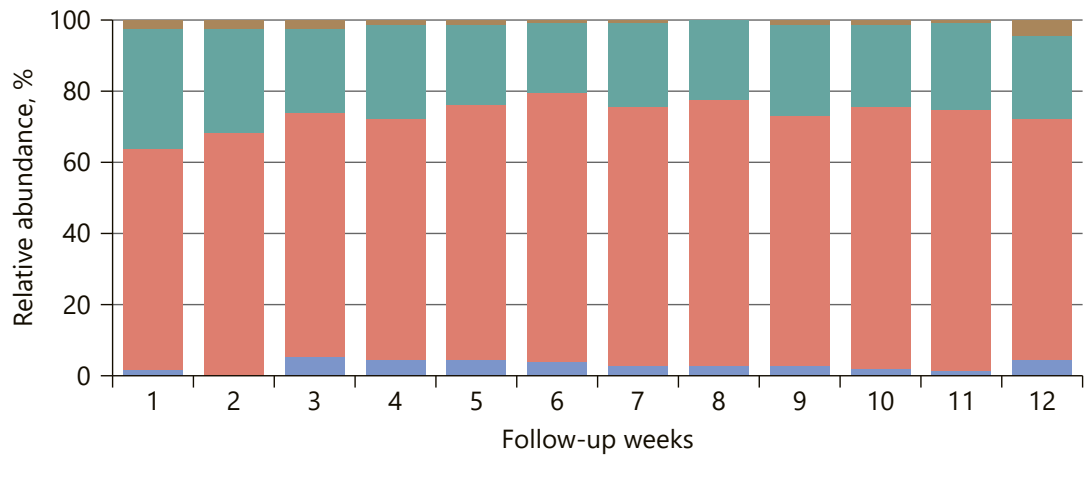

-1-7 day $\quad$ After each procedure $\square$ Every day $\square$ Missing

\section{Discussion}

In this international questionnaire survey, we found that the transmission risk of SARS-CoV-2 during endoscopic procedures was not high in appropriate PPE settings. In addition, our data suggest that the minimum
PPE to prevent the development of COVID-19 was less than expected.

In contrast to previous concerns, none of the participants developed COVID-19 when treating COVID-19 positive patients, and 1 participant developed COVID-19 when treating patients without confirmed COVID-19. 
Table 2. Endoscopic procedures and personal protective equipment used during procedures performed in patients with confirmed COVID-19 $(n=14)$

\begin{tabular}{lr}
\hline Variable & $N(\%)$ \\
\hline Endoscopic procedure & \\
$\quad$ EGD & $11(79)$ \\
Colonoscopy & $7(50)$ \\
ERCP and EUS & $10(71)$ \\
Upper GI hemostasis & $6(43)$ \\
Lower GI hemostasis & $3(21)$ \\
Upper GI ESD & $2(14)$ \\
Mask & $1(7)$ \\
No use & $3(21)$ \\
Surgical mask & $5(36)$ \\
N95 & $5(36)$ \\
Surgical mask + N95 mask & \\
Face shield and goggles & 0 \\
No use of face shield or goggles & $2(14)$ \\
Use of face shield but no goggles & $7(50)$ \\
No use of face shield but use of goggles & $5(36)$ \\
Use of face shield and goggles & \\
Cap & $6(43)$ \\
No use & $8(57)$ \\
Use & \\
Gown & $10(71)$ \\
Short-sleeved vinyl-type & \\
Short-sleeved vinyl-type + arm cover & $9(64)$ \\
Long-sleeved vinyl-type & $5(36)$ \\
Long-sleeved isolation-type & 0 \\
Gloves & $3(21)$ \\
Single pair & \\
Double pair & \\
\hline & \\
\hline
\end{tabular}

EGD, esophagogastroduodenoscopy; ERCP, endoscopic retrograde cholangiopancreatography; EUS, endoscopic ultrasound; COVID-19, coronavirus disease; GI, gastrointestinal 2019; ESD, endoscopic submucosal dissection.

There are 2 possible explanations for this discrepancy. First, most cases of nosocomial COVID-19 may occur when PPE is absent or insufficient in situations where healthcare professionals are unaware of the infection status of the patient. A recent European study also reported a low risk of COVID-19 transmission in endoscopy settings [14], which supported our findings. Another reason for the low incidence rate of COVID-19 in our study may be related to the procedure time and distance between the patient and healthcare professionals compared with other medical practices in the infectious ward. Most EGDs and colonoscopies take minutes to tens of minutes; upper and lower GI hemostasis and ERCP are completed within $1 \mathrm{~h}$, and even the longest ESD procedures are completed within a few hours. In addition, a certain distance is maintained between the patient and endoscopist, and no close contact with the patient is necessary.

The results of our survey identified the minimum PPE used during endoscopic procedures in patients diagnosed with COVID-19. With regard to masks, a surgical mask may have the potential to reduce COVID-19 transmission, and it was consistent with previous observations [15]. The use of a face shield or goggles may help prevent transmission risk via the eyes. Therefore, we suggested the use of a surgical mask, or a face shield or goggles, any type of long-sleeved gown, and a single pair of gloves as the minimum PPE when performing EGD, colonoscopy, ERCP and EUS, upper and lower GI hemostasis, and upper GI ESD procedures in COVID-19 positive patients. However, further studies to collect data from more endoscopic procedures conducted in patients with a COVID-19 over longer term observation periods are needed to elucidate the appropriate PPE to prevent the development of COVID-19 related to endoscopic procedures.

In contrast to many healthcare providers' concerns, replacement frequencies of mask, cap, and gown were maintained at the similar levels throughout the study period (Fig. 4). The most common timing to replacement was "every day" in mask and cap and "after each procedure" in gown, respectively.

This was the first longitudinal international survey to evaluate the incidence of nosocomial COVID-19 among healthcare professionals involved in endoscopic procedures. Our survey included participants from all continents except Antarctica and included both areas with high and low rates of SARS-CoV-2 infection. In addition, we used a solid questionnaire survey system to collect high-quality questionnaire data. Repeat questionnaire surveys will enable us to perform survival analyses of patients with COVID-19. However, our study had some limitations. First, the primary outcome data were collected using self-reported questionnaires only, and we did not perform additional surveys, such as collection of PCR or computed tomography data, to confirm the events to protect the privacy of the participants. In addition, we may have missed some COVID-19 events because some participants developed severe pneumonia and did not respond to the survey during the follow-up period. However, we invited participants using a personal private network among academic experts, and we are continuously collecting data. Therefore, we believe the data to be both reliable and of high quality. Second, differential diagnosis of community-acquired and endosco- 
Table 3. Endoscopic procedures and personal protective equipment used during procedures performed in patients without confirmed COVID-19

\begin{tabular}{|c|c|c|c|c|c|}
\hline Variable & $\begin{array}{l}\text { EGD } \\
n=401, n(\%)\end{array}$ & $\begin{array}{l}\text { Colonoscopy } \\
n=342, n(\%)\end{array}$ & $\begin{array}{l}\text { ERCP and EUS } \\
n=211, n(\%)\end{array}$ & $\begin{array}{l}\text { Hemostasis } \\
n=101, n(\%)\end{array}$ & $\begin{array}{l}\text { ESD } \\
n=117, n(\%)\end{array}$ \\
\hline \multicolumn{6}{|l|}{ Mask } \\
\hline No use & $28(7.0)$ & $24(7.0)$ & $13(6.2)$ & $5(5.0)$ & $8(6.8)$ \\
\hline Surgical mask & $274(68.3)$ & $231(67.5)$ & $127(60.2)$ & $62(61.4)$ & $95(81.2)$ \\
\hline N95 mask & $49(12.2)$ & $42(12.3)$ & $35(16.6)$ & $14(13.8)$ & $6(5.1)$ \\
\hline Surgical mask + N95 mask & $50(12.5)$ & $45(13.2)$ & $36(17.0)$ & $20(19.8)$ & $8(6.9)$ \\
\hline \multicolumn{6}{|l|}{ Face shield and goggles } \\
\hline No use of face shield or goggles & $49(12.2)$ & $40(11.7)$ & $34(16.1)$ & $11(10.9)$ & $12(10.3)$ \\
\hline Use of face shield but no goggles & $47(11.7)$ & $36(10.5)$ & $25(11.9)$ & $13(12.9)$ & $8(6.8)$ \\
\hline No use of face shield but use of goggles & $216(53.9)$ & $187(54.7)$ & $102(48.3)$ & $49(48.5)$ & $71(60.7)$ \\
\hline Use of face shield and goggles & $89(22.2)$ & $79(23.1)$ & $50(23.7)$ & $28(27.7)$ & $26(22.2)$ \\
\hline \multicolumn{6}{|l|}{ Cap } \\
\hline No use & $199(49.6)$ & $170(49.7)$ & $103(48.8)$ & $46(45.5)$ & $62(53.0)$ \\
\hline Use & $202(50.4)$ & $172(50.3)$ & $108(51.2)$ & $55(54.5)$ & $55(47.0)$ \\
\hline \multicolumn{6}{|l|}{ Gown } \\
\hline No use & $10(2.5)$ & $9(2.6)$ & $4(1.9)$ & $2(2.0)$ & $3(2.6)$ \\
\hline Short-sleeved vinyl-type & $45(11.2)$ & $43(12.6)$ & $28(13.3)$ & $9(8.9)$ & $10(8.6)$ \\
\hline Short-sleeved vinyl-type + arm cover & $12(3.0)$ & $12(3.5)$ & $5(2.4)$ & $4(3.9)$ & $4(3.4)$ \\
\hline Long-sleeved vinyl-type & $95(23.7)$ & $78(22.8)$ & $58(27.4)$ & $19(18.8)$ & $17(14.5)$ \\
\hline Long-sleeved isolation-type & $239(59.6)$ & $200(58.5)$ & $116(55.0)$ & $67(66.4)$ & $83(70.9)$ \\
\hline \multicolumn{6}{|l|}{ Gloves } \\
\hline Single pair & $346(86.3)$ & $296(86.5)$ & $179(84.8)$ & $82(81.2)$ & $106(90.6)$ \\
\hline Double pair & $55(13.7)$ & $46(13.5)$ & $32(15.2)$ & $19(18.8)$ & $11(9.4)$ \\
\hline
\end{tabular}

EGD, esophagogastroduodenoscopy; ERCP, endoscopic retrograde cholangiopancreatography; EUS, endoscopic ultrasound; COVID-19, coronavirus disease 2019.

py-related SARS-CoV-2 infections may be difficult. Third, our primary outcome definition was COVID-19 development, not COVID-19 pneumonia, or other symptoms development. In conclusion, the risk of COVID-19 transmission during endoscopic procedures, including EGD, colonoscopy, ERCP and EUS, upper and lower GI hemostasis, and upper GI ESD, was low in PPE settings.

\section{Acknowledgements}

We thank all the participants and their families.

\section{Statement of Ethics}

This study was approved by the Ethics Committee of the University of Tokyo Hospital (No. 2020046NI) and conducted ethically in accordance with the World Medical Association Declaration of Helsinki. Informed consents were obtained by web survey.

\section{Conflict of Interest Statement}

The authors declare no competing interests.

\section{Funding Sources}

The authors did not receive any funding.

\section{Author Contributions}

All authors contributed to the design of this study. T. Kawahara performed data management and statistical analysis. R. Niikura drafted the manuscript. All authors have read and approved the final manuscript. 


\section{References}

1 Wang C, Horby PW, Hayden FG, Gao GF. A novel coronavirus outbreak of global health concern. Lancet. 2020;395(10223):470-3.

2 Soetikno R, Teoh AYB, Kaltenbach T, Lau JYW, Asokkumar R, Cabral-Prodigalidad P, et al. Considerations in performing endoscopy during the COVID-19 pandemic. Gastrointest Endosc. 2020;92(1):176-83.

3 Chiu PWY, Ng SC, Inoue H, Reddy DN, Ling Hu E, Cho JY, et al. Practice of endoscopy during COVID-19 pandemic: position statements of the Asian Pacific Society for Digestive Endoscopy (APSDE-COVID statements). Gut. 2020;69(6):991-6.

4 Tang JW, Li Y, Eames I, Chan PK, Ridgway GL. Factors involved in the aerosol transmission of infection and control of ventilation in healthcare premises. J Hosp Infect. 2006; 64(2):100-14.

5 Johnston ER, Habib-Bein N, Dueker JM, Quiroz B, Corsaro E, Ambrogio M, et al. Risk of bacterial exposure to the endoscopist's face during endoscopy. Gastrointest Endosc. 2019;89(4):818-24.
6 Furuta T, Irisawa A, Matsumoto T, Kawai T, Inaba T, Kanno A, et al. Clinical questions and answers on gastrointestinal endoscopy during the novel COVID-19 pandemic. Dig Endosc. 29 Jul;32(5):651-7.

7 Irisawa A, Furuta T, Matsumoto T, Kawai T, Inaba $\mathrm{T}$, Kanno A, et al. Gastrointestinal endoscopy in the era of the acute pandemic of coronavirus disease 2019: recommendations by Japan Gastroenterological Endoscopy Society. Dig Endosc. 2020 Jul;32(5):648-50.

8 Lamers MM, Beumer J, van der Vaart J, Knoops K, Puschhof J, Breugem TI, et al. SARS-CoV-2 productively infects human gut enterocytes. Science. Jul 3;369(6499):50-4.

9 Leung WK, To KF, Chan PK, Chan HL, Wu $\mathrm{AK}$, Lee N, et al. Enteric involvement of severe acute respiratory syndrome-associated coronavirus infection. Gastroenterology. 2003; 125(4):1011-7.

10 Chan KH, Poon LL, Cheng VC, Guan Y, Hung IF, Kong J, et al. Detection of SARS coronavirus in patients with suspected SARS. Emerging Infect Dis. 2004;10(2):294-9.
11 Repici A, Pace F, Gabbiadini R, Colombo M, Hassan C, Dinelli M, et al. Endoscopy units and the coronavirus disease 2019 outbreak: a multicenter experience from Italy. Gastroenterology. 2020 Jul;159(1):363-6.e3.

12 Parasa S, Reddy N, Faigel DO, Repici A, Emura F, Sharma P. Global impact of the COVID-19 pandemic on endoscopy: an international survey of 252 centers from 55 countries. Gastroenterology. 2020 Oct;159(4):1579-81. e5.

13 Forster P, Forster L, Renfrew C, Forster M. Phylogenetic network analysis of SARSCoV-2 genomes. Proc Natl Acad Sci U S A. 2020;117(17):9241-3.

14 Repici A, Aragona G, Cengia G, Cantu P, Spadaccini M, Maselli R, et al. Low risk of covid-19 transmission in GI endoscopy. Gut. 2020 Nov;69(11):1925-27.

15 Boskoski I, Gallo C, Wallace MB, Costamagna G. COVID-19 pandemic and personal protective equipment shortage: protective efficacy comparing masks and scientific methods for respirator reuse. Gastrointest Endosc. 2020 Sep;92(3):519-23. 